\title{
Improved Performance of the ECR Waveguide Plasma Cathode with Permanent Magnets
}

\author{
Brandon R. Weatherford ${ }^{1}$ and John E. Foster ${ }^{2}$ \\ University of Michigan, Ann Arbor, MI, 48109
}

\begin{abstract}
The performance of the U-M waveguide plasma cathode is presented, with data acquired on argon, krypton, and xenon feed gases. The maximum electron current extracted from the device was $4.2 \mathrm{~A}$, at $100 \mathrm{~V}$ and $120 \mathrm{~W}$ of absorbed microwave power, and either $6 \mathrm{sccm}$ on argon or $2 \mathrm{sccm}$ on xenon. As expected, xenon delivered the most efficient performance, due to its low mobility and low ionization potential relative to argon and krypton. The minimum amount of power consumption (microwave power plus beam extraction power) was 89.9 W/A, and the maximum gas utilization factor was 32.2 electrons per xenon atom. Spatial maps of Langmuir probe data were recorded in the region between the plasma cathode and extraction anode (on xenon), and the resulting ion density and plasma potential distributions are discussed.
\end{abstract}

\section{Introduction}

$\mathrm{E}$ lectron sources are frequently used in electric propulsion systems, for both the ionization of propellant and the neutralization of ion beams. In these applications, the hollow cathode assembly (HCA) has been the electron source of choice, due to its high degree of power efficiency and its legacy. ${ }^{1}$ The conventional HCA is well-suited for many applications, but for long-term exploration missions to the outer planets or as a semi-permanent installation requiring long operation times, the limited lifetime of the HCA makes it a less attractive option. One inherent limitation on the lifetime of the HCA arises from the depletion of emissive material from the thermionic emitter insert, either through evaporation or cathode poisoning. ${ }^{2,3}$ Both the keeper anode and orifice in an HCA are subject to erosion by sputtering from the high-density plasma within the device. Because of these failure mechanisms, the most recent wear test of a hollow cathode neutralizer demonstrated a lifetime of 36,000 hours. ${ }^{3}$ Several alternatives to the hollow cathode have been investigated in order to extend the lifetime of the hollow cathode, including reservoir cathodes, $\mathrm{LaB}_{6}$ cathodes, carbon composition cathodes, and electrodeless plasma cathodes. ${ }^{4-7}$ Plasma cathodes are devices that extract electrons from a dense plasma source. ${ }^{8}$

The HAYABUSA spacecraft, which has successfully returned from the Itokawa asteroid, demonstrated that microwave plasma discharges can be employed as sources for both ion thrusters and neutralizers, while avoiding the lifetime limitations that arise from the use of thermionic emitters. ${ }^{9}$ The $\mu 10$ neutralizers on HAYABUSA employed electron cyclotron resonance (ECR) heating as the ionization mechanism for the plasma cathode discharge, using a wire antenna to launch the required microwaves. ${ }^{10}$ The use of an antenna in direct contact with the discharge may present another lifetime limitation in long-term missions, which arises from the erosion of the antenna itself, as the antenna is vulnerable to ion bombardment. ${ }^{11}$

Several other varieties of microwave and RF plasma cathodes have been studied for applications in electric propulsion. One example is the use of intense microwave frequency electric fields in a resonant cavity as the ionization source. ${ }^{12}$ Several others use ECR heating, in which the ionizing electrons are accelerated by the microwave electric field as they orbit around static magnetic field lines. ${ }^{10,13,14,15}$ RF plasma cathodes, which operate at a lower frequency, have been studied which use helicon ${ }^{16}$ and inductive ${ }^{17}$ discharges as the electron source.

The microwave waveguide plasma cathode presented in this paper is another variety of electrodeless plasma cathode, which can circumvent the limitations on cathode life that are associated with thermionic emitters and microwave antenna erosion. The waveguide plasma cathode generates an ECR discharge, using $2.45 \mathrm{GHz}$ microwaves and permanent magnets, within a circular waveguide geometry. The hollow cylindrical structure provides an ample amount of collection area for ions, which is required for any effective plasma cathode. The magnetic field configuration, established by permanent magnets downstream from the microwave launching

${ }^{1}$ Graduate Student, Nuclear Engineering and Radiological Sciences, Student Member AIAA.

${ }^{2}$ Associate Professor, Nuclear Engineering and Radiological Sciences, Senior Member AIAA.

American Institute of Aeronautics and Astronautics 
window, allows for the ECR heating zone to be established on the centerline of the device. The magnetic field is oriented axially in the heating zone, which allows for electron transport to the exit plane of the source without being impeded by cross-field electron diffusion.

The purpose of this paper is to present a more complete data set of the deliverable electron current from the waveguide plasma cathode on argon, and to present the corresponding data on krypton and xenon feed gases. The dependence of the source efficiency with respect to power and gas utilization is addressed as well. Spatial maps of plasma parameters within the visible plume outside the source were generated using a planar Langmuir probe. On xenon feed gas, the spatial variations of plasma density and plasma potential outside the source are investigated as a function of gas flow rate, applied bias, and absorbed microwave power.

\section{Experimental Setup}

\section{A. Plasma Source Description}

An explanation of the design process for the U-M waveguide plasma cathode is presented elsewhere, along with a more detailed description of the device. ${ }^{18}$ The body of the source, as shown in Figure 1, is a section of circular copper waveguide, with an internal diameter of $7.6 \mathrm{~cm}$ and length of $10.0 \mathrm{~cm}$. The waveguide diameter was set large enough to allow propagation of the circular $\mathrm{TE}_{11}$ waveguide mode at the microwave frequency of $2.45 \mathrm{GHz}$, but small enough to cut off propagation of higher-order waveguide modes. A steel endplate is mounted at the downstream end of the source with a $4 \mathrm{~mm}$ diameter aperture in the center, to increase feed gas utilization at low flow rates, and focus electrons into a high density area when current is extracted. The upstream end of the source is sealed by a $0.6 \mathrm{~cm}$ thick quartz pressure window. Gas is fed into the source near the pressure window, through a ring-shaped plenum, $3.2 \mathrm{~mm}$ in diameter.

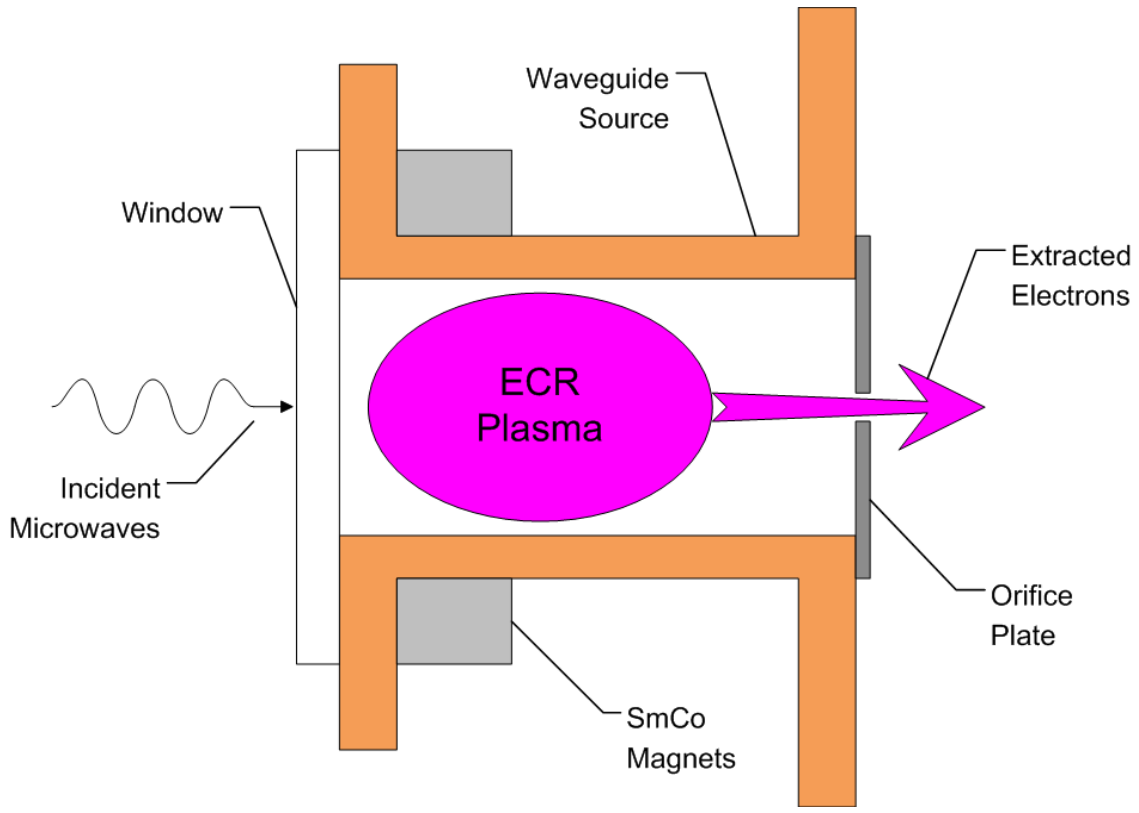

Figure 1. Sketch of the waveguide plasma cathode.

To establish the 875 Gauss magnetic field strength required for ECR breakdown at $2.45 \mathrm{GHz}$, a ring of grade 26 samarium cobalt magnets is mounted to the outside of the waveguide. The magnet ring is oriented axially, and is designed to establish the ECR heating zone on the centerline of the source, where the microwave electric field is strongest. Because of the axial orientation of the magnetic field, electron transport from the heating zone to the exit plane of the source can be achieved without electron diffusion across magnetic field lines. A contour plot of the magnetic field profile is shown in Figure 2. 
Microwaves from a magnetron are launched through a circulator, and power meters are used to measure the forward and reflected microwave power through a two-way directional coupler. A three-stub tuner is used for load matching, and a high-power microwave cable connects the tuner to a coax-to-WR340 adapter. The adapter is mounted to one end of a rectangular $\mathrm{TE}_{10}$ to circular $\mathrm{TE}_{11}$ mode waveguide transition, and the circular end is mounted to the waveguide plasma source. The quartz window is clamped between the waveguide transition and the source. The downstream end of the plasma source is mounted to a vacuum chamber with a length of $62 \mathrm{~cm}$ and inner diameter of $42 \mathrm{~cm}$. A photograph of the plasma source mounted on the chamber, with the microwave launching setup, is shown in Figure 3, and a block diagram of the microwave power circuit is shown in Figure 4.

\section{B. Diagnostics}

Two main diagnostics were used for this study. The first was a circular electrode used to measure the amount of electron current that could be extracted from the source. The electrode is a circular molybdenum disc with a diameter of $12 \mathrm{~cm}$, and it was placed in the vacuum chamber, $14 \mathrm{~cm}$ from the end of the plasma source. The electrode was biased positive relative to the plasma source, using a $100 \mathrm{~V}, 5 \mathrm{~A}$ DC power supply. The applied voltage and extracted current were measured with two multimeters. A schematic of the current extraction circuit is shown in Figure 5.

A planar Langmuir probe was also used to take spatially resolved measurements of the plasma parameters in the visible plume between the extraction aperture and the molybdenum anode. The probe, made of tungsten, has a diameter of $3.18 \mathrm{~mm}$, and is surrounded by alumina tubing with an outer diameter of $3.5 \mathrm{~mm}$. The probe was mounted on a 1-D translation stage, and could be translated along the centerline of the plasma source. Probe traces were recorded and analyzed by a data acquisition software package on a PC.

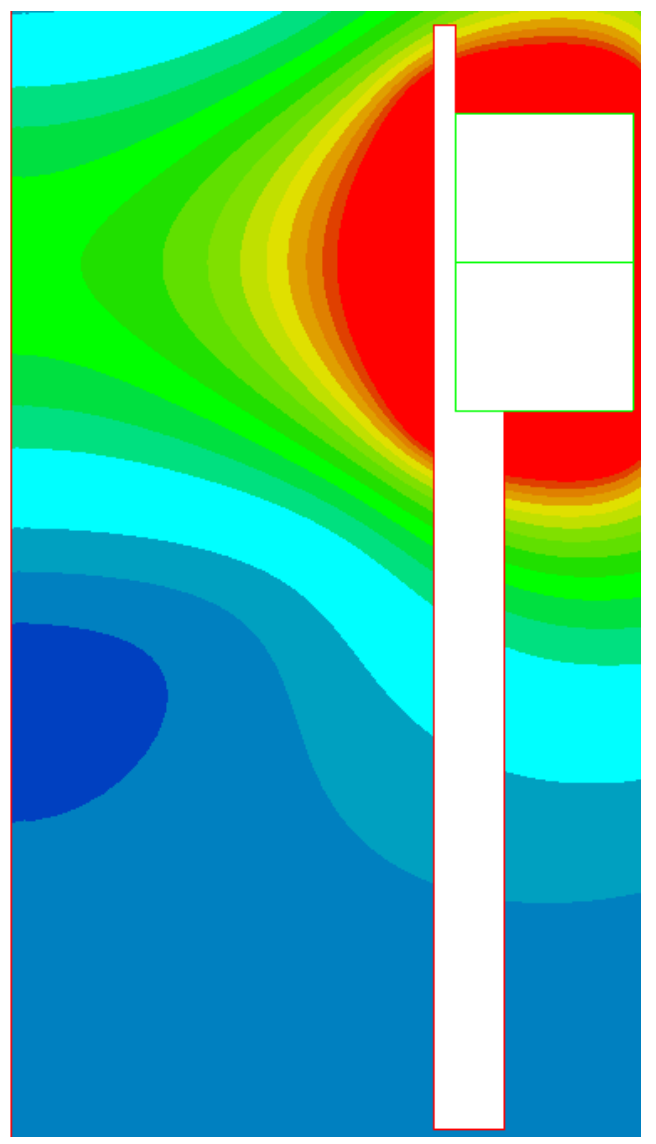

Figure 2. Contour plot of magnetic field strength within waveguide. Leftmost edge is waveguide axis. ECR heating zone shown in bright green.

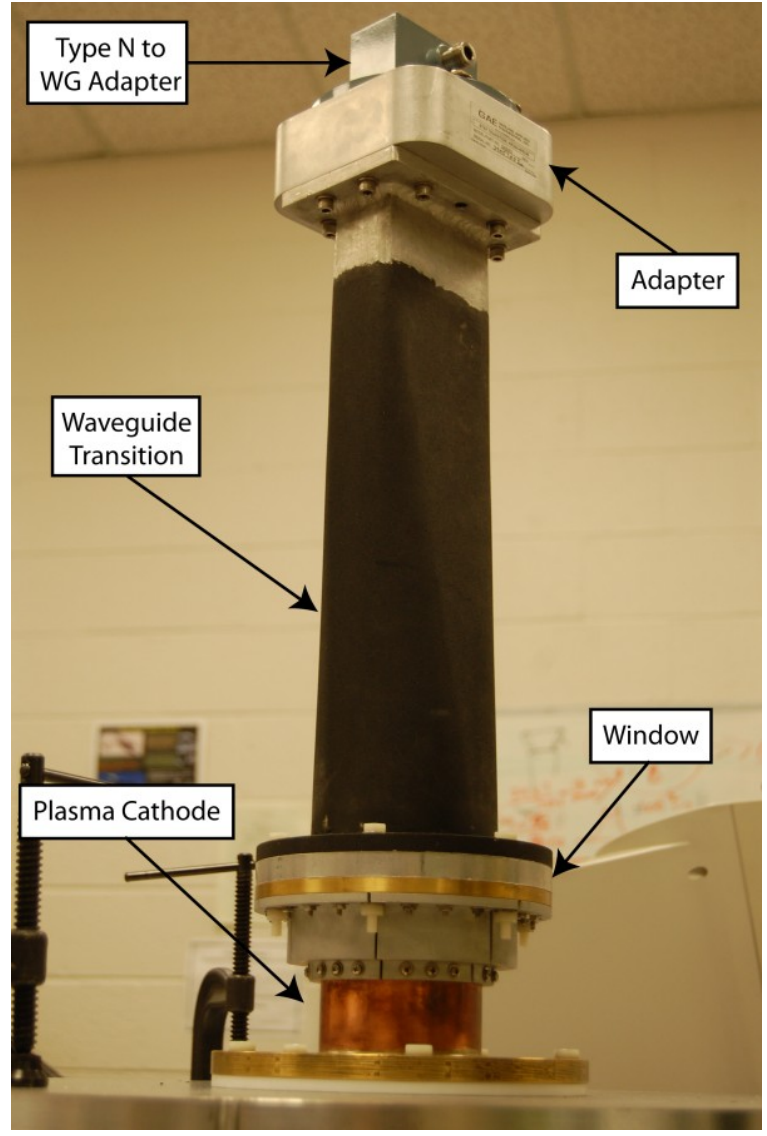

Figure 3. Photograph of the plasma source and testing facility.

3

American Institute of Aeronautics and Astronautics 


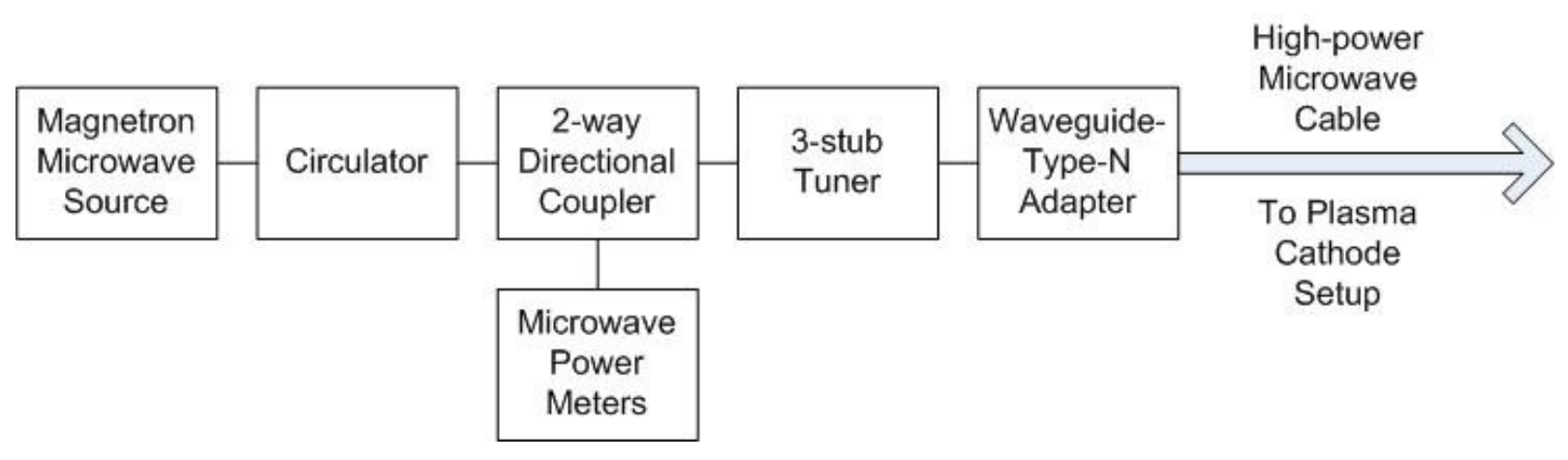

Figure 4. Block diagram of microwave power circuit.

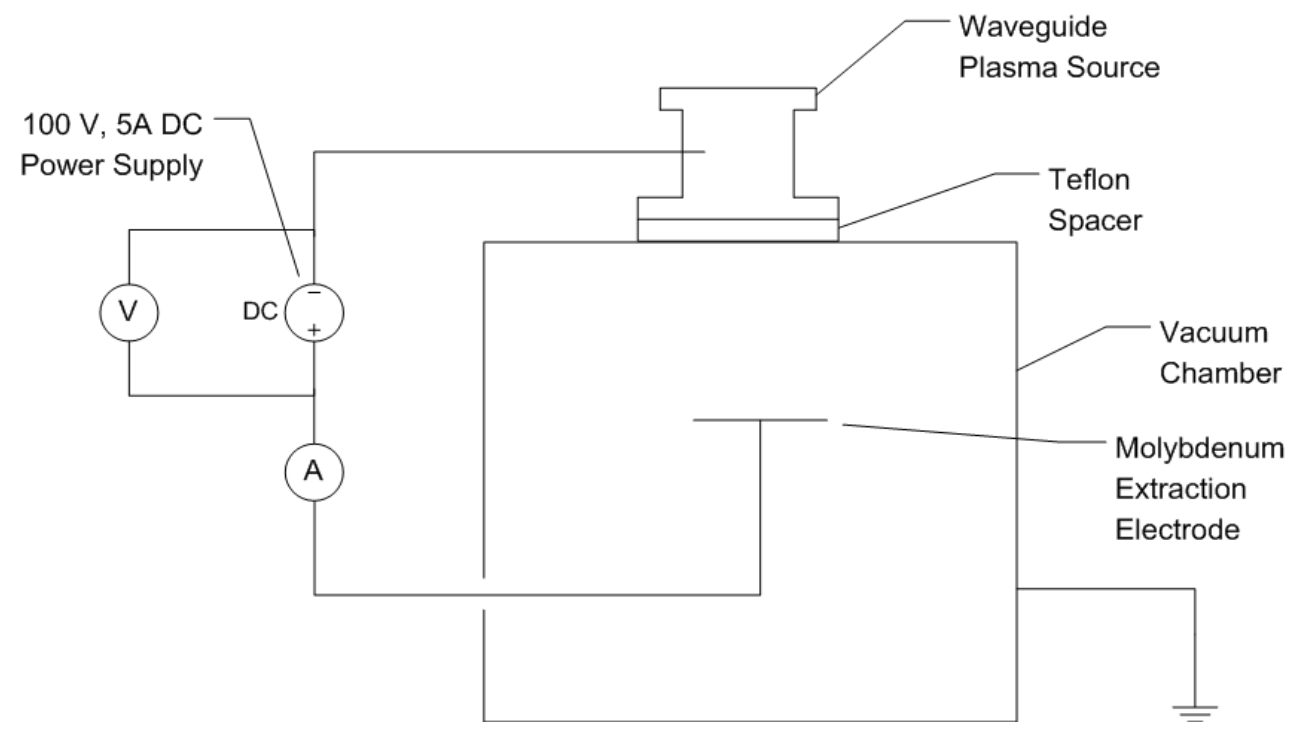

Figure 5. Schematic of electron current extraction circuit.

\section{Results and Analysis}

\section{A. Current Extraction - Argon, Krypton, and Xenon}

The waveguide plasma cathode was benchmarked by measuring the amount of extractable electron current as a function of absorbed microwave power, gas flow rate, and applied anode bias, on argon, krypton, and xenon feed gases. Argon was the first gas to be tested. The source was operated at three different anode voltages: $60 \mathrm{~V}, 80 \mathrm{~V}$, and $100 \mathrm{~V}$. At each bias, current was extracted as the argon flow rate was varied between 2 and $8 \mathrm{sccm}$, and the absorbed microwave power was varied from $40 \mathrm{~W}$ to $120 \mathrm{~W}$, in increments of $20 \mathrm{~W}$. The results are shown in Figure 6 . 


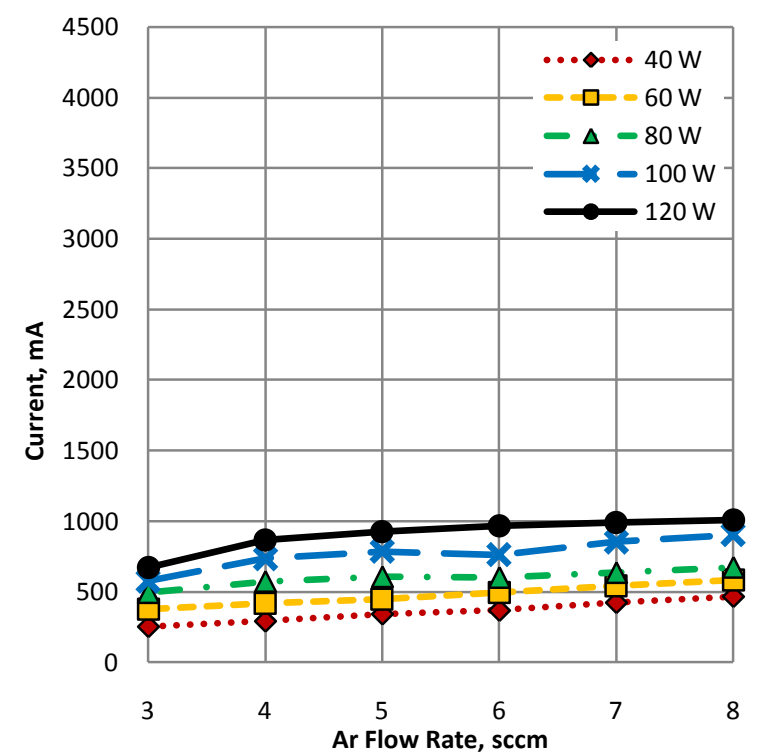

a)

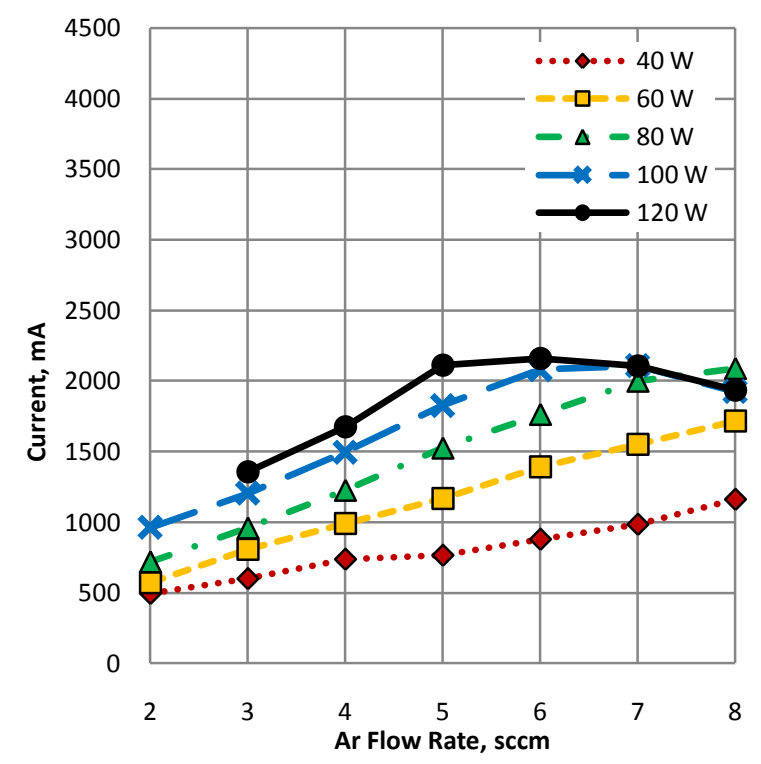

b)

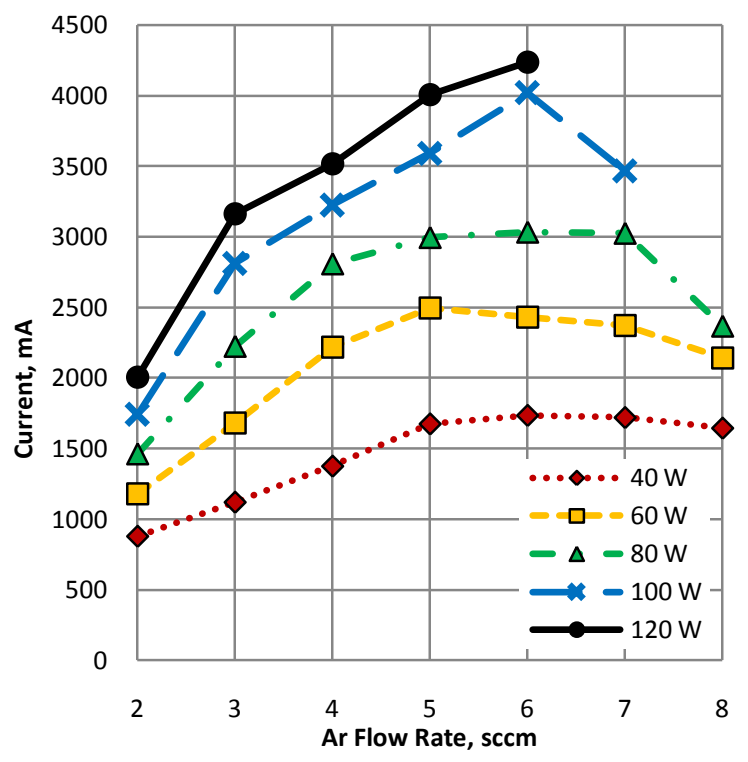

c)

Figure 6. Extracted electron currents versus microwave power and argon flow rate, for $4 \mathbf{m m}$ extraction orifice, and electrode bias of: a) $60 \mathrm{~V}$, b) $80 \mathrm{~V}$, and c) $100 \mathrm{~V}$.

The maximum amount of extracted current was $4.2 \mathrm{~A}$, at a bias of $100 \mathrm{~V}$, and flow rate of $6 \mathrm{sccm}$ on argon, and $120 \mathrm{~W}$ of absorbed microwave power. There is another key point to take from the plots in Figure 6. At $100 \mathrm{~V}$ (and $80 \mathrm{~V}$, at high power) the current profile is peaked around $6 \mathrm{sccm}$. At the upper end of this range of flow rates, the internal source pressure is approaching $65 \mathrm{mTorr}$. As the pressure is increased, electron diffusion away from the ECR heating zone will increase through electron-neutral collisions, and this may be partially responsible for the decrease in performance at higher flow rates. Additionally, as the collision frequency increases, the electron temperature decreases, which will decrease the amount of ionization from high-energy electrons in the tail of the distribution. Plasma density measurements within the source should be useful in determining whether this explanation for the peaked current profile is correct.

A similar series of current extraction measurements were taken on krypton feed gas, but with krypton, the applied bias range was from $40 \mathrm{~V}$ to $80 \mathrm{~V}$. The results are shown in Figure 7. 


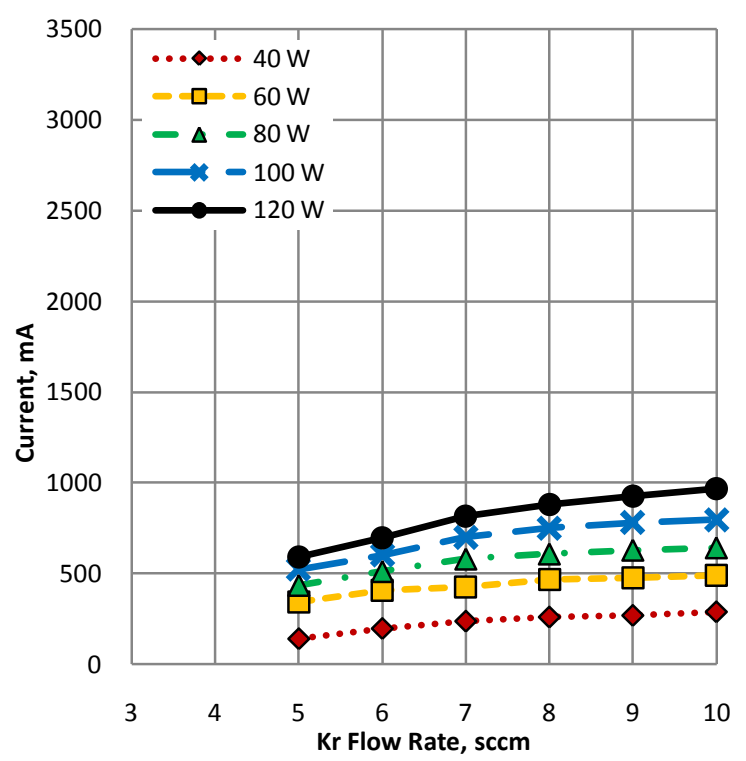

a)

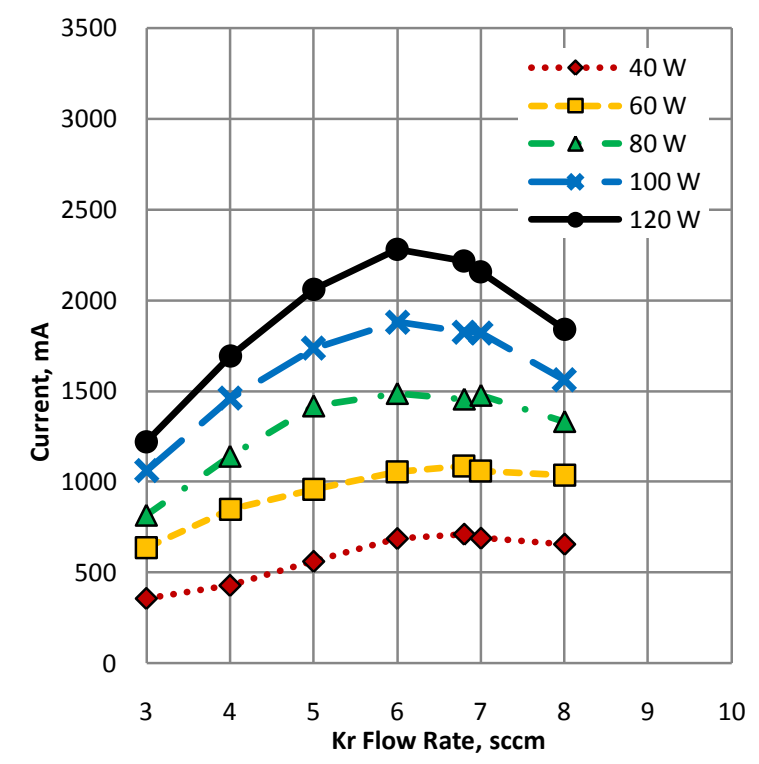

c)

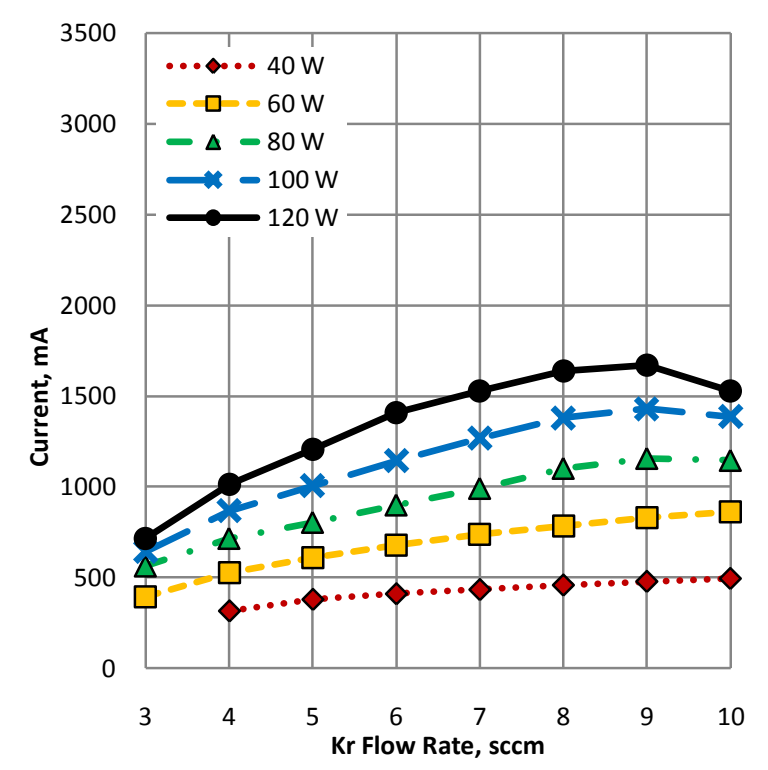

b)

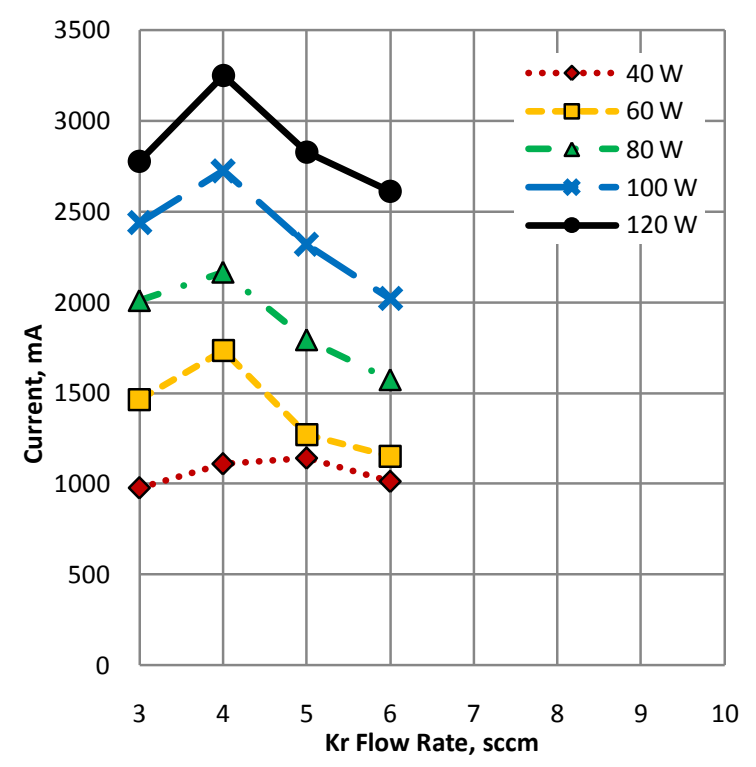

d)

Figure 7. Extracted electron current versus microwave power and krypton flow rate, for $4 \mathbf{m m}$ extraction orifice, and electrode bias of: a) $40 \mathrm{~V}$, b) $50 \mathrm{~V}$, c) $60 \mathrm{~V}$, and d) $80 \mathrm{~V}$.

With krypton, the maximum amount of extracted electron current was $3.3 \mathrm{~A}$, at $80 \mathrm{~V}, 120 \mathrm{~W}$ absorbed power, and $4 \mathrm{sccm}$. Though more current was extracted on argon, the $4.2 \mathrm{~A}$ mark on argon was reached only at a bias of $100 \mathrm{~V}$. Rather, at a bias of $80 \mathrm{~V}$, the maximum amount of current extracted on argon (Figure 6) was 2.1 A, at 120 $\mathrm{W}$ and a flow rate of $6 \mathrm{sccm}$. This marks an increase in peak current of 55 percent when switching from argon to xenon at $80 \mathrm{~V}$. Additionally, the gas flow rate corresponding to the peak current shifts from $6 \mathrm{sccm}$ (argon) to 4 sccm (krypton). The increase in extractable current at fixed bias and microwave power is expected because of the lower ionization potential of krypton relative to argon. Also, the shift to a lower flow rate can be explained by the fact that krypton neutrals have a larger mass than argon, and are therefore less mobile. This will result in a decreased conductance across the extraction aperture relative to argon. At a given flow rate, the internal source 
pressure will be higher on krypton than on xenon, and if the optimal gas pressure is similar between the two gases, the krypton current profiles will shift to lower flow rates relative to argon.

Another interesting aspect of the current profiles in Figure 7 is the gradual change in the current profile shape as the bias in increased from $40 \mathrm{~V}$ to $80 \mathrm{~V}$. At $40 \mathrm{~V}$, the current generally increases monotonically up to a flow rate of $10 \mathrm{sccm}$. As the bias in increased, the curves become more peaked, with the peak gradually shifting to a lower flow rate. At $80 \mathrm{~V}$, the peak has shifted to a flow rate of $4 \mathrm{sccm}$, where the peak value of $3.3 \mathrm{~A}$ is measured. This behavior with respect to flow rate generally holds true regardless of microwave power - as power is increased, the extracted current increases, as expected.

The same current profiles were also recorded with xenon feed gas, and the results are shown in Figure 8. With xenon, the applied bias was varied from $40 \mathrm{~V}$ to $100 \mathrm{~V}$. In the $100 \mathrm{~V}$ case, the bias was only turned on for a few seconds at a time, as opposed to the other voltages, when the bias was left on constantly. The maximum amount of extracted current on xenon was $4.2 \mathrm{~A}$, at $2 \mathrm{sccm}$, a bias of $100 \mathrm{~V}$ and $120 \mathrm{~W}$ of absorbed microwave power, while at $80 \mathrm{~V}$, the maximum current was $3.3 \mathrm{~A}$. Interestingly, this peak current at $80 \mathrm{~V}$ is the same as on krypton, but as expected, at a lower flow rate $(2 \mathrm{sccm})$. The peak current at $100 \mathrm{~V}$ is the same as for argon at $100 \mathrm{~V}(4.2 \mathrm{~A})$. This seems to suggest that at each of these voltages, the amount of extracted current may be reaching its upper limit - the expected increase in current due to the lower ionization potential of xenon does not appear to happen at all. If the internal plasma density is not significantly higher on xenon than on the other gases, then the limiting factor may be the internal surface area of the plasma cathode. The wall area is necessary to maintain current continuity by collecting a total amount of ion current equal to the extracted electron current through the aperture, and the ion current density at the walls of the source is limited by the Bohm current through the sheath. As a rough estimate, if a uniform plasma density of $10^{11} \mathrm{~cm}^{-3}$ is assumed within the source, with an electron temperature of $3 \mathrm{eV}$, the total amount of collected ion current would be $1.0 \mathrm{~A}$, and the extractable current would be limited by the ion collection area. However, a plasma with a density of $10^{12} \mathrm{~cm}^{-3}$ would be able to deliver $10.0 \mathrm{~A}$ of electron current before becoming wall area-limited. In order to definitively know whether the current is wall-limited, the spatial ion density profiles at the walls of the source should be used to calculate an integrated ion current at the walls, but the extracted current data shown in Figure 8 are within this range of values where wall area limitations may be a factor. 


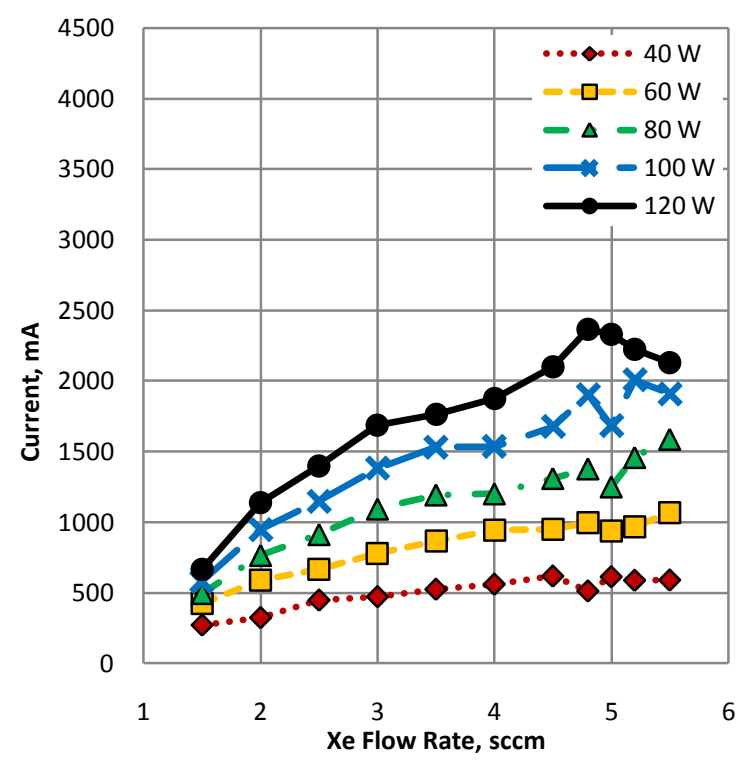

a)

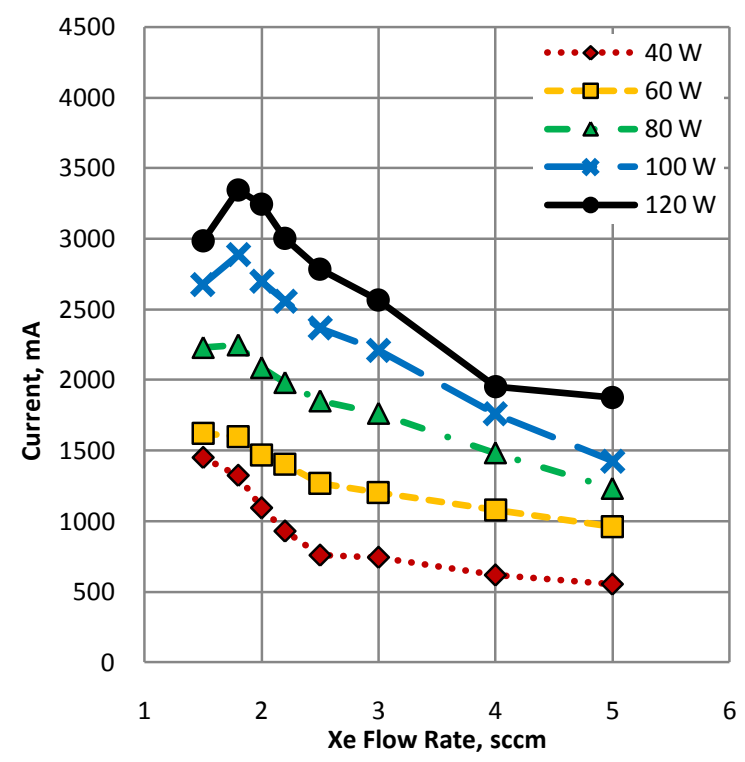

c)

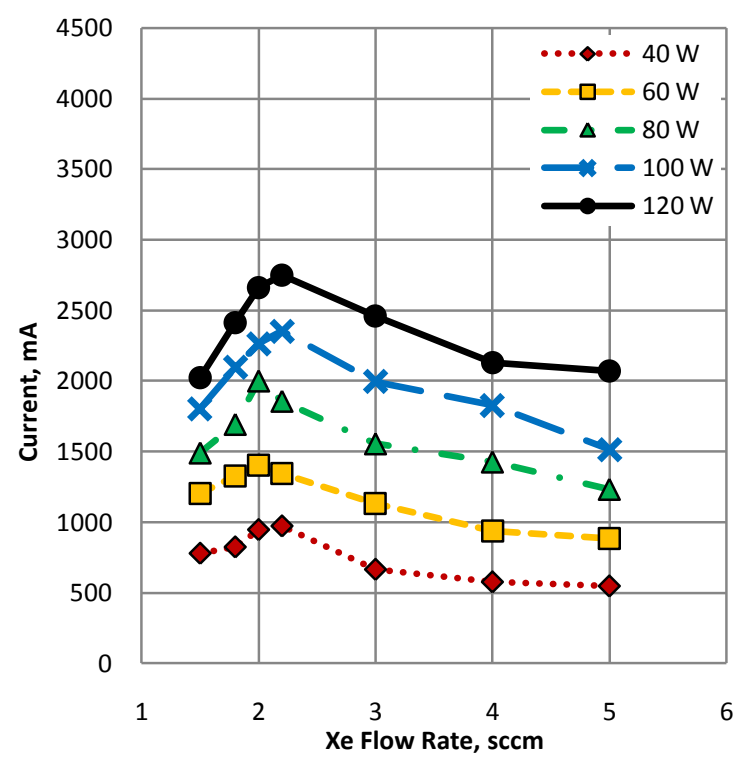

b)

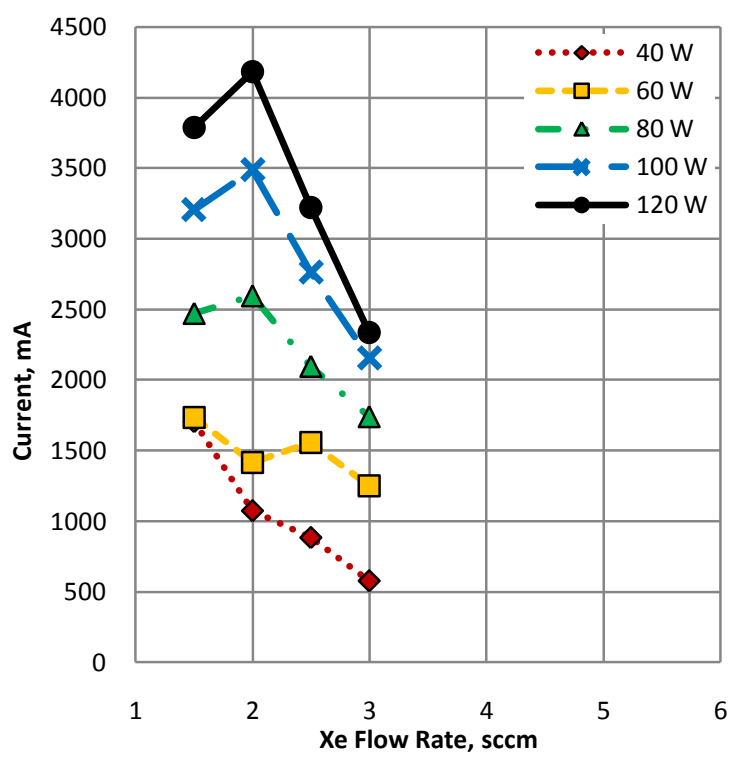

d)

Figure 8. Extracted electron current versus microwave power and xenon flow rate, for 4 mm extraction orifice, and electrode bias of: a) $40 \mathrm{~V}$, b) $60 \mathrm{~V}$, c) $80 \mathrm{~V}$, and d) $100 \mathrm{~V}$.

In contrast to the current profiles on krypton, which show a gradual shift in optimal flow rate to lower flows as the voltage is increased, the change is much more sudden on xenon. At a bias of $40 \mathrm{~V}$, the peak current on xenon occurs at a flow rate around $5 \mathrm{sccm}$, but at $60 \mathrm{~V}$ and above, the peak is shifted to around 1.5 to $2 \mathrm{sccm}$, where the maximum currents are extracted at high voltage. The shift from a peak at $4 \mathrm{sccm}$ on krypton to $2 \mathrm{sccm}$ on xenon is likely explained by the lower mobility of xenon relative to krypton, resulting in a higher internal pressure at a given flow rate. The sudden mode change between the $40 \mathrm{~V}$ and $60 \mathrm{~V}$ operating conditions is not yet understood, but a future study of the spatial plasma distribution inside the device at the two biases may clarify this behavior. 


\section{B. Figures of Merit}

Two figures of merit related to the efficiency of the waveguide plasma cathode were calculated for all of the xenon data. The first figure is the total power consumption, defined as the absorbed microwave power plus beam extraction power, normalized to the extracted current. The total power consumption is shown in Figure 9 for xenon at $80 \mathrm{~V}$, as a function of microwave power and flow rate. The data show that there is a clear optimum flow rate (or internal pressure), and this corresponds to the peak extracted current at $2 \mathrm{sccm}$. At $80 \mathrm{~V}$, the minimum total power consumption was 100 $\mathrm{W} / \mathrm{A}$, at a flow rate of $2 \mathrm{sccm}$ and $80 \mathrm{~W}$ of absorbed microwave power.

The second figure of merit is the gas utilization factor, which is defined as the extracted electron current normalized to the equivalent current of neutral gas flow through the device. The gas utilization factor at $80 \mathrm{~V}$ is plotted in Figure 10 as a function of microwave power and flow rate, and the maximum utilization factor at 80 $\mathrm{V}$ was 18.8 electrons produced per neutral. Utilization factors of this magnitude imply that there is large degree of ion recycling within the plasma cathode, where a neutral is ionized, the corresponding electron is extracted, and the ion recombines at the cathode wall. This process can repeat many times for each injected neutral, which can result in a high gas utilization efficiency.

There is a change in behavior of the utilization factor above $2 \mathrm{sccm}$ relative to the data points at $2 \mathrm{sccm}$ or less. At the lower flow rates, the gas utilization is nearly independent of flow rate, and in this case, the source may be running in a power-limited regime. At higher flow rates, the utilization monotonically decreases with flow, suggesting that the drop in electron temperature at higher pressure is suppressing the total ionization rate within the device; and this effect appears in the current extraction data as well.

A scatter plot of the total power consumption versus the gas utilization factor is shown in Figure 11, for all data points taken on xenon, at biases ranging from 40 to $100 \mathrm{~V}$, flow rates from 1 to $5 \mathrm{sccm}$, and microwave power levels from $40 \mathrm{~W}$ to $120 \mathrm{~W}$. The overall best power efficiency (lowest power consumption) was achieved at a $40 \mathrm{~V}$ bias, and had a value of $89.8 \mathrm{~W} / \mathrm{A}$. The largest degree of gas utilization was achieved at $100 \mathrm{~V}$ bias, and had a value of 35.2 electrons per neutral. As shown by Figure 11 and Table 1, the waveguide plasma cathode is capable of operating in a highly power-efficient mode (especially at 40-50 V), in a mode with high gas utilization (especially at high bias), or at several points which compromise between both power and gas efficiency.

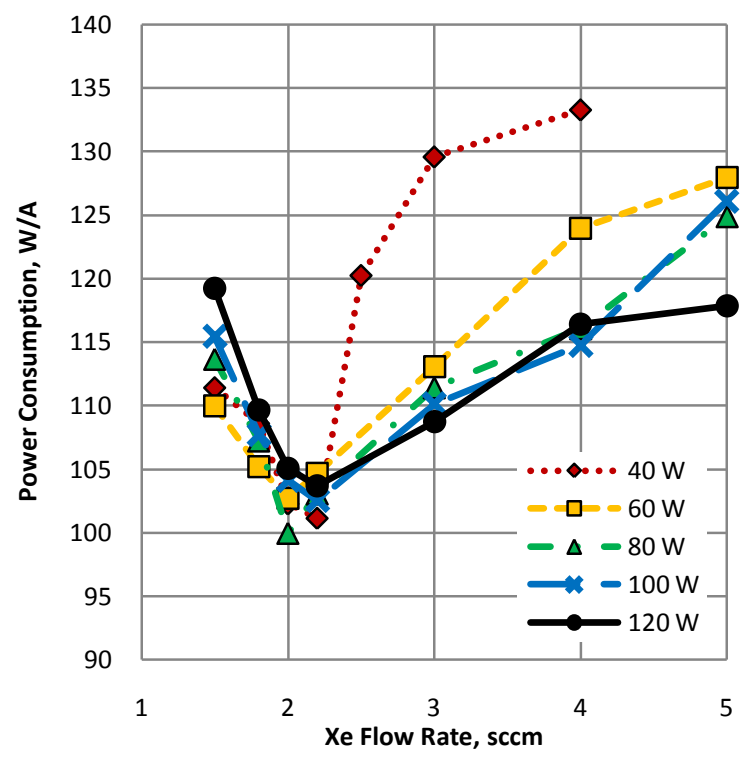

Figure 9. Total power consumption, on Xe feed gas, at $80 \mathrm{~V}$ bias

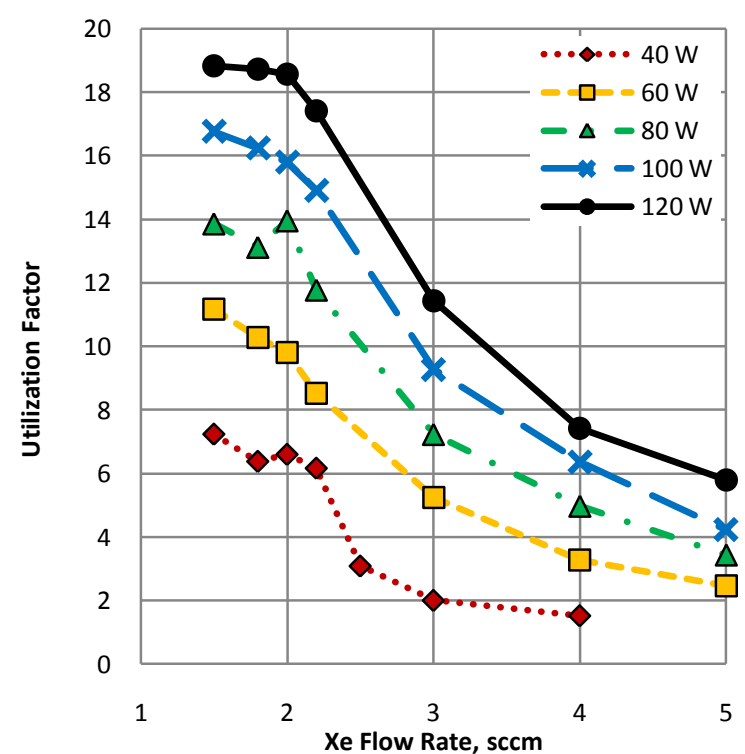

Figure 10. Gas utilization factor, on Xe feed gas, at $80 \mathrm{~V}$ bias 
Table 1. Source performance at optimal operating conditions.

\begin{tabular}{|c|c|c|c|}
\hline $\begin{array}{l}\text { Operating } \\
\text { Condition } \\
\end{array}$ & $\frac{\text { Current }}{\text { [A] }}$ & $\begin{array}{c}\begin{array}{c}\text { Power } \\
\text { Consumption }\end{array} \\
{[\mathbf{W} / \mathbf{A}]}\end{array}$ & $\begin{array}{c}\text { Gas } \\
\text { Utilization } \\
\text { Factor }\end{array}$ \\
\hline Current & 4.2 & 129 & 29.2 \\
\hline Power Efficiency & 2.0 & 90 & 5.4 \\
\hline Gas Efficiency & 3.8 & 132 & 35.2 \\
\hline
\end{tabular}

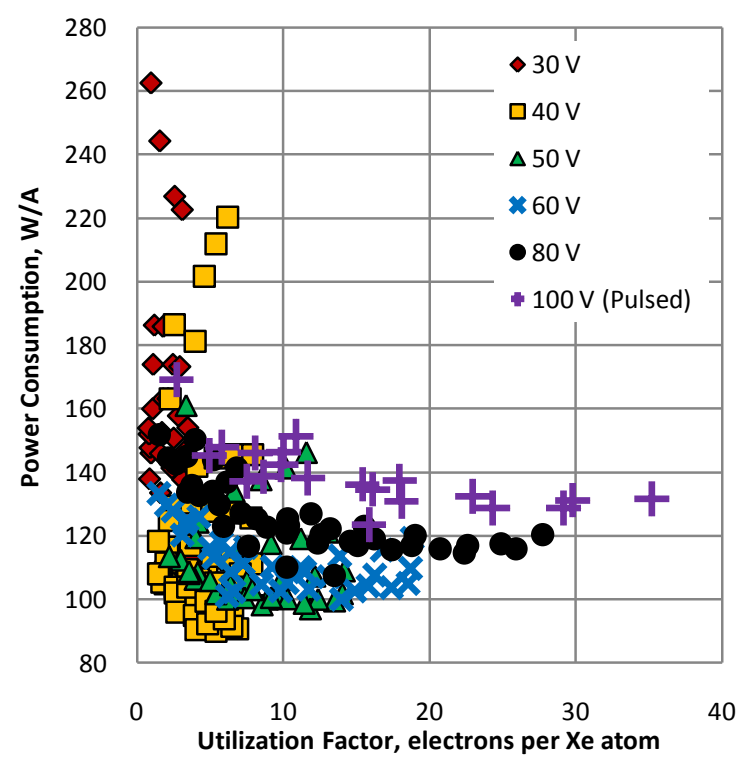

Figure 11. Scatter plot of total power consumption vs. gas utilization factor on Xe, for all data points.

\section{Langmuir Probe Traces in Plume - Xenon}

When the source is in operation, there is a visible plume which eminates from the extraction aperture and fills the region between the aperture and the extraction anode. In order to study the characteristics of the plasma in this region, Langmuir probe traces were recorded every $6.35 \mathrm{~mm}$, starting at the extraction anode and ending when the plume was extinguished due to the probe obstructing the area downstream from the aperture. An understanding of the plasma density and potential distributions in the anode-cathode gap will be useful in designing an optimized electron extraction circuit, possibly with the use of an annular keeper anode. The plasma density was calculated at each location from the ion saturation current, and the plasma potential was estimated from the root of the second derivative of the I-V trace, near the knee in the curve.

The first series of measurements on xenon was collected at an absorbed microwave power of $60 \mathrm{~W}$ and applied bias of $60 \mathrm{~V}$, in order to study the effect of xenon flow rate on the visible plume. The results are shown in Figure 12. At all flow rates, the plasma density drops by an order of magnitude within a few centimeters of the aperture, as the plasma expands into the vacuum chamber. The density profile at $2 \mathrm{sccm}$ drops off more rapidly than at higher flow rates, as the pressure gradient at low flow is not as high. At 4 and $6 \mathrm{sccm}$, the dense plasma region extends further into the gap, and this change in the spatial plasma distribution has an effect on the plasma potential profile. As seen in Figure $12 \mathrm{~b}$ ), at $2 \mathrm{sccm}$, the plasma potential gradually increases as the anode is approached, starting at $22 \mathrm{~V}$ at $1.4 \mathrm{~cm}$ and reaching $39 \mathrm{~V}$ near the anode - a total rise of $17 \mathrm{~V}$ in that region. The lower ion density at 2 sccm, coupled with the large electron current extracted at this flow rate, should establish a potential gradient in this region. At higher flow rates, the ions extend further into the gap, which will tend to flatten the potential profile. However, since the plasma potential in the gap is around 60-75 percent of the applied bias at higher flow, electrons in the gap have presumably been accelerated in the region near the orifice, because the surfaces of the plasma cathode are held at zero Volts. 


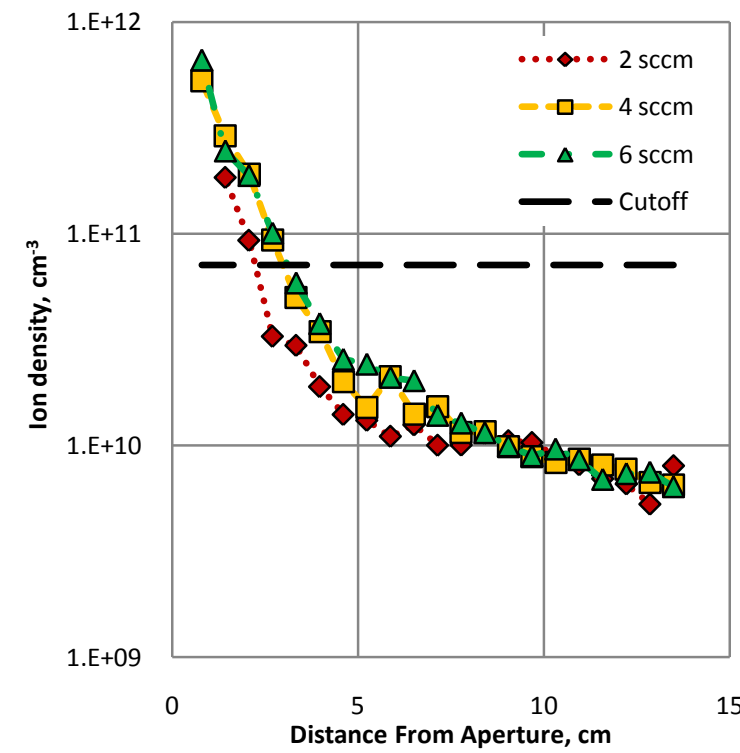

a)

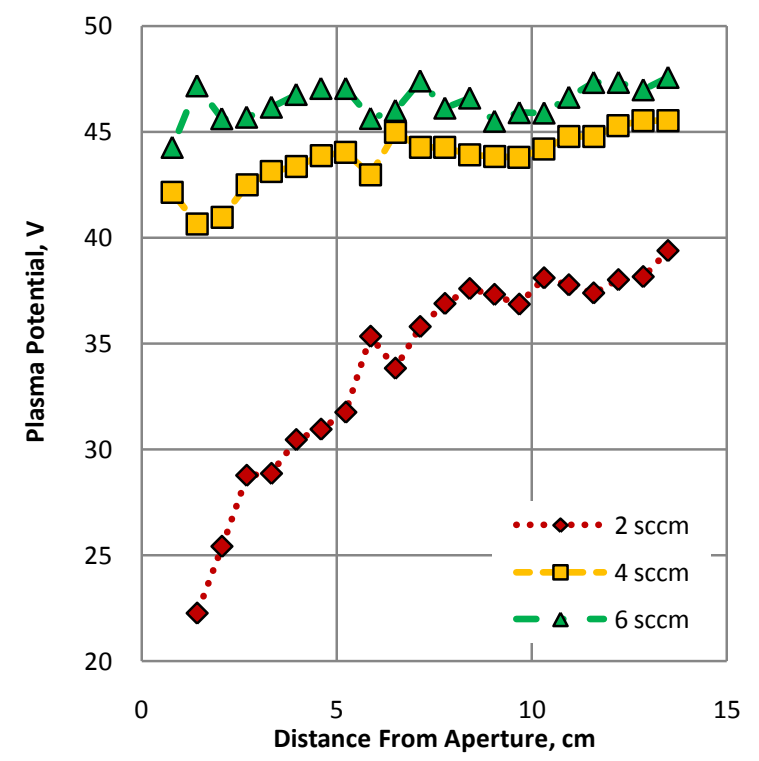

b)

Figure 12. Spatial dependence of a) plasma density and b) plasma potential on Xe flow rate, in the external plume, at $60 \mathrm{~V}$ and $60 \mathrm{~W}$ absorbed microwave power.

The next series of probe traces was used to investigate the dependence on microwave power, at a fixed bias of 60 $\mathrm{V}$, and $2 \mathrm{sccm}$ of xenon. The results are shown in Figure 13. At this bias and flow rate, the absorbed microwave power does not appear to influence the general shape of the ion density distribution - increased microwave power just shifts the ion density at all locations upward, but does not change the degree of uniformity within the gap. The shape of the plasma potential profile is generally the same as well, with the potential increasing by 10 to $15 \mathrm{~V}$ in the region where measurements were taken. There is an interesting decrease in the plasma potential near the anode at high power levels, but the reasons for this are unclear. Future analysis of electron densities in the plume, calculated from the electron energy distribution functions, will provide additional information about the reasons for these potential profiles. 


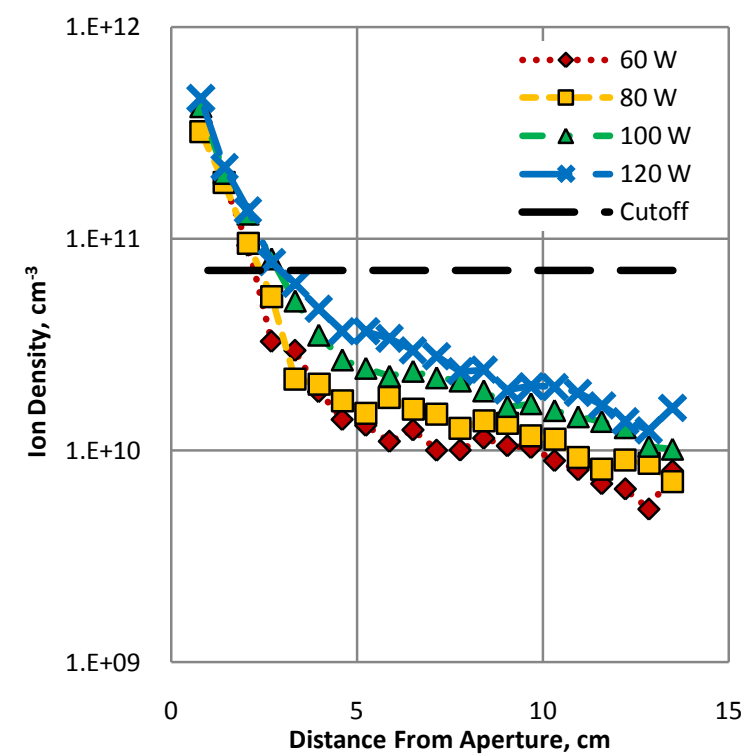

a)

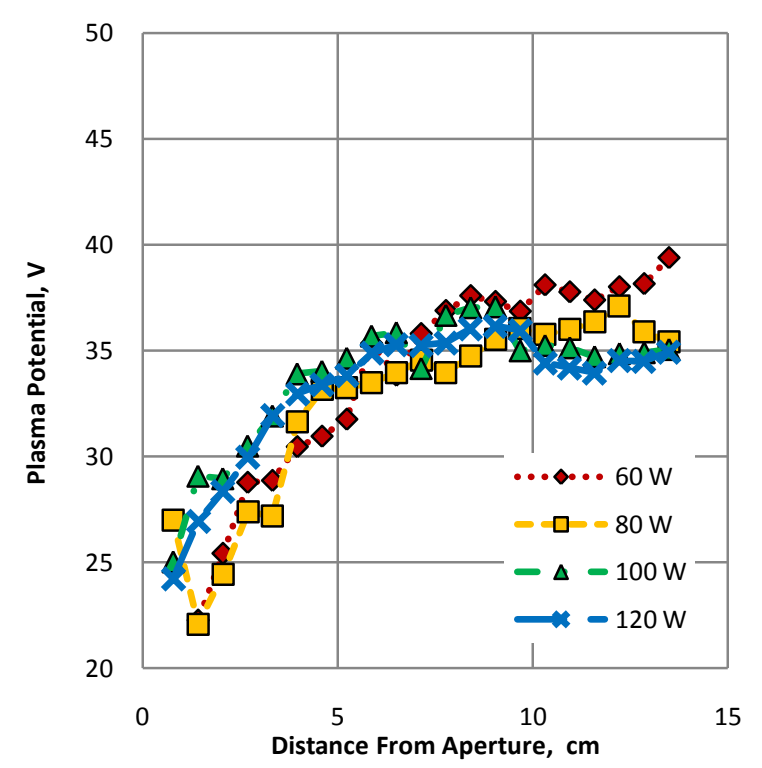

b)

Figure 13. Spatial dependence of a) plasma density and b) plasma potential on absorbed microwave power, at $2 \mathrm{sccm}$ Xe flow and $60 \mathrm{~V}$ bias.

Another set of Langmuir probe data was acquired at $2 \mathrm{sccm}$ and $60 \mathrm{~W}$ of microwave power, while varying the anode bias; the plasma density and plasma potential from these measurements are shown in Figure 14. This set of data is somewhat limited, due to the fact that the plume was extinguished when the probe was located quite far from the aperture. However, some conclusions can be drawn from this data. The ion density within the gap tends to increase as the positive anode bias is increased in magnitude. As electrons are extracted from the source, some ions will be pulled into the gap along with them due to the ambipolar electric field. It is difficult to make any definitive statements about the shapes of the plasma potential profiles from this data, but at all cases, electrons from the cathode should be accelerated, since the plasma potential in the gap varies from 50 percent (at $40 \mathrm{~V}$ bias) to 75 percent (at $80 \mathrm{~V}$ bias) of the anode potential.

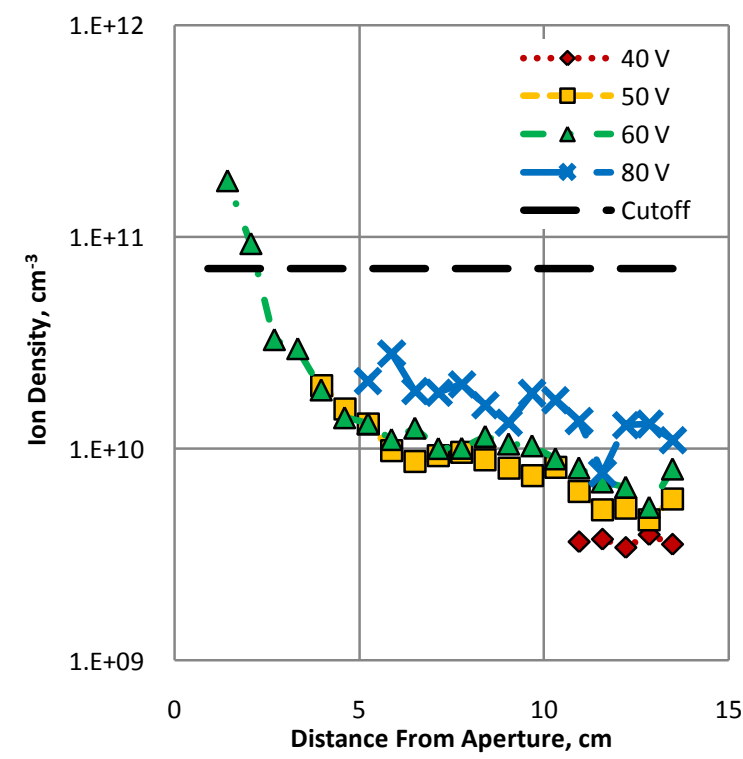

a)

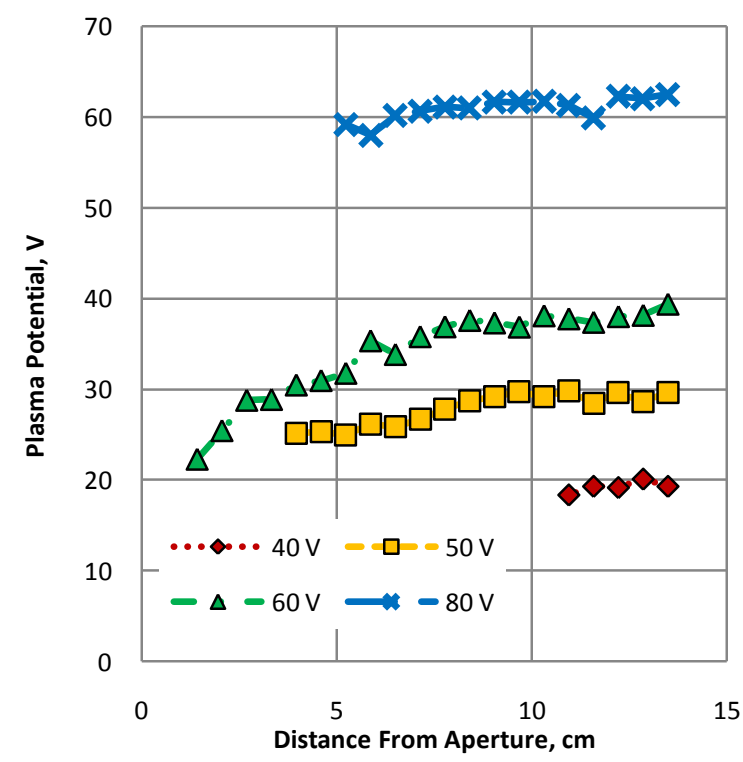

b)

Figure 14. Spatial dependence of a) plasma density and b) plasma potential on bias, at $2 \mathrm{sccm}$ Xe flow and $60 \mathrm{~W}$ absorbed microwave power. 


\section{Conclusions}

The waveguide plasma cathode developed at U-M is a device capable of efficiently supplying electron current, with respect to both gas and power utilization, without the lifetime limitations associated with thermionic emitters or wire antennas in direct contact with the discharge within the device. Argon, krypton, and xenon feed gases were tested in the device, and as expected, xenon delivered the best overall performance. The source has been operated in high current, gas-efficient, and power-efficient regimes, and a balance between these parameters can be achieved by varying the gas flow, microwave power, and extraction bias. Langmuir probe data within the plume suggests that the ion density and plasma potential within the cathode-anode gap are sensitive to gas flow rate through the source. At a fixed bias and microwave power, increasing the argon gas flow rate from $2 \mathrm{sccm}$ to $6 \mathrm{sccm}$ resulted in overdense plasma extending $1 \mathrm{~cm}$ further downstream from the extraction aperture, and reduced the long-range plasma potential gradient in the gap to just a few tenths of a Volt per centimeter. By contrast, the plasma potential profile in the gap is generally independent of microwave power at fixed flow and bias. While there is evidence of a non-quasineutral plasma within portions of the gap, additional measurements of electron density and electron energies will be useful in explaining the behavior of the plasma plume eminating from the waveguide plasma cathode. After the potential profiles within the plume are well-understood, that information can then be used to design an optimized electron extraction circuit with a keeper anode, which may increase the total power efficiency of the device.

\section{Acknowledgments}

The authors thank Dr. Hani Kamhawi at NASA Glenn Research Center for his support in this work. This work is supported in part by the NASA Graduate Student Researchers Program Fellowship.

\section{References}

${ }^{1}$ Rawlin, V.K., and Kerslake, W.R.," SERT II: Durability of the Hollow Cathode and Future Applications of Hollow Cathodes," J. Spacecraft, Vol. 7, No. 1, 1970.

${ }^{2}$ Sarver-Verhey, T.R., "Destructive Evaluation of a Xenon Hollow Cathode After a 28,000 Hour Life Test," Proc.34 $4^{\text {th }}$ AIAA/ASME/SAE/ASEE Joint Propulsion Conference and Exhibit, Cleveland, OH, July 13-15, 1998, AIAA Paper 2003-5279

${ }^{3}$ Sengupta, A., et. al, "An Overview of the Results from the 30,000 $\mathrm{Hr}$ Life Test of Deep Space 1 Flight Spare Ion Engine," Proc.40th AIAA/ASME/SAE/ASEE Joint Propulsion Conference and Exhibit, 11 - 14 July 2004, Fort Lauderdale, FL, AIAA Paper 2004-3812

${ }^{4}$ Vaughn, J., et. al, "NEXIS Reservoir Cathode 2000 Hour Proof-of-Concept Test," Proc.40th AIAA/ASME/SAE/ASEE Joint Propulsion Conference and Exhibit, 11 - 14 July 2004, Fort Lauderdale, FL, AIAA Paper 2004-4203

${ }^{5}$ Goebel, D., Watkins, R., and Jameson, K., "LaB 6 Hollow Cathodes for Ion and Hall Thrusters," Journal of Propulsion and Power, Vol. 23, No. 3, May-June 2007, pp. 552-558

${ }^{6}$ Hakayawa, Y., et. al, "Graphite Orificed Hollow Cathodes for Xenon Ion Thrusters," Proc. 43rd AIAA/ASME/SAE/ASEE Joint Propulsion Conference and Exhibit, 8-11 July, 2007, Cincinnati, OH, AIAA Paper 2007-5173

${ }^{7}$ Foster, J., "The High Power Electric Propulsion (HiPEP) Ion Thruster," Proc. 40th AIAA/ASME/SAE/ASEE Joint Propulsion Conference and Exhibit, 11 - 14 July 2004, Fort Lauderdale, FL, AIAA Paper 2004-3812

${ }^{8}$ Oks,E.M., "Physics and technique of plasma electron sources," Plasma Sources Sci. and Technol., Vol. 1, 249,1992

${ }^{9}$ Kuninaka, et al., "Powered Flight of HAYABUSA in Deep Space," Proc. 42nd AIAA/ASME/SAE/ASEE Joint Propulsion Conference and Exhibit, 9-12 July, 2006, Sacramento, CA, AIAA Paper 2006-4318

${ }^{10}$ Kininaka, H. and Satori, S., "Development and Demonstration of a Cathodeless Electron Cyclotron Resonance Ion Thruster," Journal of Propulsion and Power, Vol. 14, No. 6, Nov-Dec. 1998, pp. 1022-1026

${ }^{11}$ Sang Wook-Kim, "Endurance Test of Microwave Engine," Proc. 40th AIAA/ASME/SAE/ASEE Joint Propulsion Conference and Exhibit, 11 - 14 July 2004, Fort Lauderdale, FL, AIAA Paper 2004-4126

${ }^{12}$ Diamant, K., "Resonant Cavity Hollow Cathode," Proc. 41 st AIAA/ASME/SAE/ASEE Joint Propulsion Conference and Exhibit, 10-13 July, 2005, Tucson, AZ, AIAA Paper 2005-3662

${ }^{13}$ Edgar, M. C., and Bilén, S. G., "Design and Testing of a High Power Electron Cyclotron Resonance Neutralizer," Proc. 43rd AIAA/ASME/SAE/ASEE Joint Propulsion Conference and Exhibit, 8-11 July, 2007, Cincinnati, OH, AIAA Paper 2007-5289

${ }^{14}$ Kamhawi, H., Foster, J., and Patterson, M., "Operation of a Microwave Electron Cyclotron Resonance Cathode," Proc. 40th AIAA/ASME/SAE/ASEE Joint Propulsion Conference and Exhibit, 11-14 July, 2004, Fort Lauderdale, FL, AIAA Paper $2004-3819$

${ }^{15}$ Diamant, K., "Microwave Cathode for Air Breathing Electric Propulsion," Proc. $31^{\text {st }}$ International Electric Propulsion Conference, 20-24 Sept., 2009, Ann Arbor, MI, Paper No. IEPC-2009-015

${ }^{16}$ Longmier, B. and Hershkowitz, N., "Improved Operation of the Nonambipolar Electron Source," Rev. Sci. Instruments, Vol. 79, Sept. 2008, 093506

${ }^{17}$ Raitses, Y., Hendryx, J., and Fisch, N., "A Parametric Study of Electron Extraction from a Low Frequency Inductively Coupled RF-Plasma Source," Proc. $31^{\text {st }}$ International Electric Propulsion Conference, 20-24 Sept., 2009, Ann Arbor, MI, Paper No. IEPC-2009-024 
${ }^{16}$ Weatherford, B. and Foster, J., "Initial Performance of a ECR Waveguide Plasma Cathode with Permanent Magnets," Proc. $31^{\text {st }}$ International Electric Propulsion Conference, 20-24 Sept., 2009, Ann Arbor, MI, Paper No. IEPC-2009-211 